
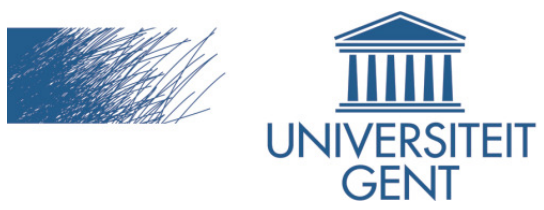

biblio.ugent.be

The UGent Institutional Repository is the electronic archiving and dissemination platform for all UGent research publications. Ghent University has implemented a mandate stipulating that all academic publications of UGent researchers should be deposited and archived in this repository. Except for items where current copyright restrictions apply, these papers are available in Open Access.

This item is the archived peer-reviewed author-version of:

When Transport Geography Meets Social Psychology: Toward a Conceptual Model of Travel Behaviour

Van Acker, V., van Wee, B. \& Witlox, F.

In: Transport Reviews, 30 (2), 219-240, 2010.

doi: 10.1080/01441640902943453

To refer to or to cite this work, please use the citation to the published version:

Van Acker, V., van Wee, B. \& Witlox, F. (2010). When Transport Geography Meets Social Psychology: Toward a Conceptual Model of Travel Behaviour. Transport Reviews 30(2), 219-240. doi: 10.1080/01441640902943453 


\section{WHEN TRANSPORT GEOGRAPHY MEETS SOCIAL PSYCHOLOGY: TOWARD A CONCEPTUAL MODEL OF TRAVEL BEHAVIOUR}

VERONIQUE VAN ACKER*, BERT VAN WEE \& FRANK WITLOX*

\footnotetext{
* Department of Geography, Ghent University, Krijgslaan 281/S8, 9000 Ghent, Belgium E-mails: veronique.vanacker@ugent.be; frank.witlox@ugent.be

- Faculty of Technology, Policy and Management, Delft University of Technology, Jaffalaan 5, 2628 BX Delft, The Netherlands.

E-mail: g.p.vanwee@tudelft.nl
} 
Abstract Many studies model the effects of the built environment on travel behaviour. Usually, results are controlled for socio-economic differences and sometimes sociopsychological differences among respondents. However, these studies do not mention why after all a relationship should exist between travel behaviour and spatial, socio-economic and personality characteristics. Answering this query involves combining and linking theories stemming from transport geography (e.g., time geography, activity-based approach) and social psychology (e.g., theory of planned behaviour, theory of repeated behaviour). Using key-variables from these theories, this paper aims to develop a conceptual model for travel behaviour. Comparable to customary theories in transport geography, this conceptual model considers travel behaviour as derived from locational behaviour and activity behaviour. But the conceptual model adds concepts such as 'lifestyle', 'perceptions', 'attitudes' and 'preferences' which indirectly influence travel behaviour.

\section{Introduction}

Living, working, shopping and recreating are spatially separated activities. In order to participate in these activities, people have to travel. Policymakers try to control and manage this daily travel behaviour, for instance through urban planning. In this respect, concepts of the New Urbanism in the United States and the Compact City Policy in Europe aim at reducing car use and travel distances because high-density and mixed-use neighbourhoods are believed to be associated with shorter trips and more non-motorized trips.

Numerous empirical studies try to measure the effects of the built environment on people's daily travel behaviour. Literature reviews such as van Wee (2002) or Ewing and Cervero (2001) distinguish various built environment characteristics, ranging from aggregated measures such as density and diversity calculated within zones such as census tracts, to more disaggregated measures such as characteristics of the respondent's dwelling. The results are generally controlled for socio-economic and demographic differences among individuals and households. A limited number of studies takes attitudes and preferences toward urban form and/or travel into account as well (e.g., Collantes and Mokhtarian, 2007; Bagley and Mokhtarian, 2002; Kitamura et al., 1997; Handy, 1996). Consequently, key-variables in these empirical travel studies refer: (i) spatial characteristics, (ii) socio-economic characteristics and (iii) socio-psychological characteristics.

Nevertheless, almost none of the empirical studies presents a theoretical framework that justifies the relationships between daily travel behaviour and spatial, socio-economic and socio-psychological characteristics. One exception is Boarnet and Crane (2001) and Crane (1996) who developed a simple theoretical framework in which they argue that the built environment influences travel behaviour through its influence on travel costs. Based on the utility maximization principle of microeconomics, they reasoned that travel choices are based on an assessment of (i) the individual's preferences for particular trips or travel modes and (ii) the relative costs of making those trips or choosing those travel modes. Doing so, they tend to consider travel choices as well-reasoned choices whereas other studies (e.g., Gardner, 2009; Verplanken et al., 1994, 1998) stress that unreasoned behaviour appears as well. Moreover, utility maximization does not totally encompass the motivation of human behaviour (Talvitie, 1997). Establishing a more comprehensive framework would, therefore, involve combining and linking theories stemming from not only microeconomics, but also from transport geography and social psychology. According to Handy (2005), theories in transport geography refer to the mechanism determining travel behaviour, whereas theories in social psychology define specific factors influencing travel behaviour. This paper aims to develop a conceptual model of travel behaviour by using key-concepts and variables from these theories. We clearly do not restrict ourselves to one particular disciplinary perspective. The 
resulting conceptual model will unravel the relationships between people's daily travel behaviour and spatial, socio-economic and socio-psychological characteristics. Doing so, we try to provide an authoritative and up-to-date review of theories and research on daily travel behaviour.

The paper is structured as follows. First, we briefly explore the theoretical concepts from transport geography in which daily travel behaviour is considered as part of a decision hierarchy. Because we are interested in a better understanding of how people travel, we limit our approach to disaggregate theories. Theories with an aggregated approach such as gravity models do not provide enough insights into the mechanisms underlying people's travel behaviour (Hanson and Schwab, 1986). Next, we introduce the quintessence of those theories in social psychology focussing on underlying factors which influence the previously described decision hierarchy. Then, we consider the conceptual framework within a social and spatial context. This is followed by a discussion of the conceptual and modelling implications of our conceptual model of travel behaviour. Finally, we summarize our main findings and point to some avenues for further research.

\section{Why travel behaviour is part of a decision hierarchy}

Daily travel patterns are often suggested to be the result of a hierarchical decision structure (e.g., Salomon and Ben-Akiva, 1983; Salomon, 1981; Ben-Akiva, 1973). This hierarchy ranges from short-term decisions on daily activities and travel, to long-term decisions on lifestyle. Our conceptual model of daily travel behaviour also departs from this notion and, therefore, the decision hierarchy is at the centre of Figure 1. In this section, we provide a theoretical justification of this decision hierarchy. In addition, some empirical results are summarized that support the theoretical justification and illustrate some recent developments.

\subsection{Short-term activity decisions and implications for travel behaviour}

Nowadays, travel is generally considered as a derived demand. Although sometimes people might travel just 'for fun' (e.g., Mokhtarian and Salomon, 2001; Mokhtarian et al., 2001), people mainly travel in order to access desired activities in other places. After all, activities such as living, working, shopping and recreating are in most cases spatially separated and, thus, encourage the need to travel. Consequently, activity behaviour which refers to the spatial and temporal characteristics of the performed activities must be studied first in order to understand travel behaviour (McNally, 2000; Axhausen and Gärling, 1992; Jones et al., 1990; Pas, 1980). This idea has been further elaborated in the activity-based approach, which emerged in the 1970s following changes in the transportation policy environment. This is to say that in transportation policy the emphasis shifted from long-term infrastructure expansion strategies to shorter-term infrastructure management strategies such as alternate work schedules, telecommuting and congestion pricing. Understanding travellers' responses to such short-term transportation policies needed a more behavioural-oriented activity-based modelling approach which was lacking in the previously used trip-based models (McNally, 2000; Bhat and Koppelman, 1999a; Jones et al., 1990).

Seminal theoretical contributions have been made by Hägerstrand (1970), Chapin (1974) and Cullen and Godson (1975).

Hägerstrand (1970) advanced time-geography in which constraints on activity participation are highlighted within a spatiotemporal framework. Researcher should focus on the spatial aspects of the individual's activity pattern as well as the temporal aspects of it. Therefore Hägerstrand (1970) introduced the concepts of space-time paths and space-time prism. The space-time path traces the spatiotemporal position of the individual's activity pattern and travel behaviour. The path is a three-dimensional representation where a two-dimensional 
horizontal plane embodies geographic locations and a vertical axis embodies time. Contrary to a vertical line, a sloped line of the path symbolizes movement over space. This path is, however, limited in space and in time. For example, due to difference in velocity different locations are within reach of the pedestrian compared to the motorist. Thus, only a particular set of locations in space and time is available. This set is known as the space-time prism and is determined by the location and duration of activities, an individual's time budget, and the travel velocities allowed by the transportation system. Whereas the path describes the observed movement throughout space and time of an individual, the prism indicates what portions of space are accessible for an individual at each moment in time (Neutens et al., 2007a; Miller, 1991; Lenntrop, 1976).

Such a space-time prism is easy to construct for one person. However, it becomes more difficult when the activity pattern of several persons must be analyzed. Hägerstrand and most studies in time geography, therefore, focus on constraints that influence time-space paths and prisms. These constraints are (i) capability constraints, (ii) coupling constraints, and (iii) authority constraints. Capability constraints refer to limitations because of physiological necessities such as sleeping, eating and personal care. Coupling constraints define where, when and for how long an individual can interact with other individuals. Authority constraints limit access to either space locations or time locations (e.g., business hours of a shop).

Whereas Hägerstrand (1970) explained the observed activity patterns within a spatiotemporal framework, Chapin (1974) described a motivational framework in which activity patterns result from the interaction between individual propensities and perceived opportunities to engage in activities. He argued that individuals perform activities to meet their basic needs, which determines the propensity to engage in activities. These engagement propensities are not autonomous; they can be facilitated as well as constrained. Facilitating factors refer to individuals' motivations and ways of thinking that predispose individuals to participate in activities, whereas constraining factors do the opposite. Examples of constraining factors are role and personal characteristics such as household responsibilities, gender and age. As a result, Chapin (1974) suggested that different socio-economic groups adopt different activity patterns. This fact clearly justifies the incorporation of a socioeconomic component in empirical studies on travel behaviour. In addition to propensity factors, opportunities are important as well to understand activity patterns. Doing so, Chapin (1974) considers activity patterns not only as the result of a "demand" phenomenon, but also of a "supply" consideration. Opportunities refer to the availability of facilities and services, as well as the quality of those facilities and services. By taken opportunities into account, Chapin could assess the impact of the built environment on activity patterns. However, he never fully developed this line of thought. Due to data limitations, Chapin's empirical research primarily concentrated on the propensity factors (Ettema and Timmermans, 1997).

The theoretical frameworks of Hägerstrand (1970) and Chapin (1974) seem complementary: Hägerstrand focussed on spatial and temporal constraints, whereas Chapin emphasized the influence of opportunities and choices (Ettema and Timmermans, 1997). Cullen and Godson (1975) attempted to combine both frameworks. They characterized the spatial and temporal constraints identified by Hägerstrand by varying degrees of flexibility. Temporal constraints are less flexible than spatial constraints. Moreover, flexibility is closely related to activity type. For example, work-related activities are less flexible than leisure activities, and routine-like activities tend to be fixed in space and time. Whereas most other activity-based studies analyze the revealed activity patterns, Cullen and Godson (1975) also tried to explain the underlying activity scheduling process. Particular activities, such as working activities, act as "pegs" around which other activities are arranged according to their flexibility. They also suggested that activities can be planned consciously or more routine-like (Lee and McNally, 2003; Bhat and Koppelman, 1999b; Ettema and Timmermans, 1997). 
Since the 1970s, considerable progress has been made in activity-based travel research (for a recent review, see, e.g., Buliung and Kanarogloy, 2007; Algers et al., 2005). One important development is the focus on intra-household and social interactions. The individual is the primary unit of analysis in most activity-based travel studies, but attention recently shifted toward the complex interactions between household members and how this influences activity and travel behaviour (e.g., Schwanen et al., 2007; Schwanen, 2007, 2008a; Srinivasan and Bhat, 2005; Gliebe and Koppelman, 2005; Voysha et al., 2004; Scott and Kanaroglou, 2002). Moreover, the individual also interacts with individuals outside the household, such as friends and colleagues. It is conceivable that the use of telecommunication technologies such as cell phones and the Internet alter joint activities with friends and colleagues and, thus, also influence travel behaviour. A growing research body exists on the performance of these joint activities (e.g., Srinivisan and Bhat, 2008; Páez and Scott, 2007; Neutens et al., 2007b, 2008). Another important development highlights day-to-day variability in activity and travel behaviour. Since data from long-duration travel diaries become available (e.g., 6-week travel diary Mobidrive in Germany), it is possible to analyze how activity and travel behaviour varies from day to day. Research indicates that travel behaviour is neither totally variable nor totally routine. Activity and travel behaviour of workers is relatively stable on weekdays, contrary to nonworkers' weekday activities and travel behaviour and to all individual's weekend activities and travel (Kitamura et al., 2006; Susilo and Kitamura, 2005; Schlich and Axhausen, 2003).

\subsection{Medium-term location decisions and implications for travel behaviour}

In the previous section travel behaviour is considered as the result of daily decisions on activity participation. However, medium-term decisions on locational behaviour such as more significant location choices such as residence and workplace also influence daily travel behaviour. Fried et al. (1977) and Cullen (1978) provided a theoretical justification for this.

In their synthesized theory on travel behaviour, Fried et al. (1977) related travel behaviour directly to activity behaviour. The distribution of activity opportunities is considered an important influence of activity and travel behaviour. Nevertheless, it is possible that the available activity opportunities do not match the individual's current activity needs. In this case, an adaptation process tries to reduce this imbalance. Adaptations range from short-term travel and activity adjustments to longer term changes such as residential or workplace relocation. Such longer term changes only occur if short-term adjustments do not sufficiently reduce the imbalance between activity opportunities and needs. Cullen (1978) stressed that longer term changes are not frequently made, but are well-reasoned and determine the context in which daily activity behaviour is performed. Consequently, longer term changes have a considerable influence on everyday activity and travel behaviour. Contrary to longer term behaviour, Cullen (1978) considered daily activity behaviour as routinely. Activity patterns can, thus, be studied by focussing on habits or recurrent routine activities. After all, daily activities are frequently made and, therefore, are not always consciously well-considered.

Since the 1970s, empirical research continued on the relationship between travel behaviour and these medium-term location decisions. Particularly, the influence of residential location choice attained attention. A number of studies (e.g., Scheiner, 2006; Clark et al., 2003; Levinson, 1997) point out that mode use, travel distances and activity behaviour all change after a residential relocation. At the same time, residential relocations can occur because of dissatisfying routines of mode use, as well as distances and locations of daily activities. The complex interdependencies of travel and residential location choices challenge the question whether the characteristics of the residential neighbourhood it selves influence travel behaviour. Several recent studies (e.g., Mokhtarian and Cao, 2008; Chen et al., 2008; Pinjari et al., 2007; Cao et al., 2007a, b; Bhat and Guo, 2007; Schwanen and Mokhtarian, 2005a, b) 
argue that attitudes and preferences toward travel, activities and residential neighbourhoods are the true determinants of travel patterns. This refers to the self-selection mechanism: individuals and households self-select themselves into a residential neighbourhood that is consistent with their attitudes and preferences. Consequently, location behaviour is not only influenced by locational preferences but also by activity and travel preferences. For example, a household with public transport preferences will likely choose a residential neighbourhood with good public transport services.

Most empirical studies do not simultaneously consider the residential and workplace location choice. One choice is assumed exogenous and influences the other choice dimension. A recent example of integrating both spatial choices is Waddell et al. (2007). By combining latent market segmentation with discrete choice models, they were able to model the interdependencies of residential and workplace location choices within the context of an integrated activity location and travel forecasting framework.

Previously mentioned studies are cross-sectional. During the last decades, more longitudinal data became available, which resulted in the emergence of a new research field in transportation research namely the analysis of "mobility biographies". This research field focuses on changes in travel behaviour over the individual's life course. Daily travel behaviour is assumed to be relatively stable, but it changes significantly in the context of key events in the life course, such as residential or workplace relocation. Mobility biographies are, thus, embedded in other biographies such as a residential biography, an employment biography and a household biography (Beige and Axhausen, 2008; Frandberg, 2008; Scheiner, 2007; Prillwitz et al., 2007).

\subsection{Long-term lifestyle decisions and implications for travel behaviour}

The longest term decision is the choice of a lifestyle. Short-term activity decisions and medium-term location decisions are made by the individual to satisfy his or her lifestyle decision. This way, lifestyle also influences daily travel behaviour. The concept of lifestyle refers to an individual's way of living and is influenced by his or her outlook of life and motivations, including beliefs, interests and general attitudes. The impact of lifestyle on travel behaviour has certainly increased. During the last decennia, prosperity increased, resulting in more available possibilities to choose from. Moreover, the social burden to behave uniformly disappeared because of increasing individualization and decreasing social control. These processes allow people to lead a personal lifestyle (Bootsma et al., 1993; Ferge, 1972). Consequently, taking lifestyles into account may result in interesting insights in travel behaviour.

Despite its frequent colloquial use, a distinct lifestyle theory is hard to find. Lifestyle is elaborated pragmatically, rather than theoretically. Especially marketing studies (e.g., Mitchell, 1983) use the concept of lifestyle in order to retrieve market sectors. These studies generally analyze numerous data by explorative statistics, such as cluster analysis. Each cluster is then referred to as another lifestyle. Because a sound theoretical basis is lacking and results are data-dependent, each study "finds" new lifestyles. This pragmatic approach is criticized by Sobel (1983) among others. Nevertheless, some theoretical contributions to the lifestyle concept are made by Weber (1972), Bourdieu (1984) and Ganzeboom (1988).

Weber (1972) is one of the first sociologists that contributed to the debate on lifestyles. He criticized Marx' class theory, in which behaviour is determined by the economic position of the individual (i.e., the possession of means of production). Weber (1972) concluded that behaviour cannot be explained by social class exclusively. Therefore, he added the concept of status, which refers to a group of people that shares the same prestige and obtain a similar lifestyle. Lifestyle is considered as a pattern of observable and expressive behaviours. 
Consequently, people with the same status, and thus the same lifestyle, will tend to behave similarly.

Following Weber (1972), Bourdieu (1984) considered lifestyle as a pattern of behaviours indicating the social position of the individual. Each individual occupies a position in a twodimensional social space which is defined by the amount and the composition of capital. The amount of capital ranges from no capital to much capital, the composition of capital ranges from economic capital to socio-cultural capital. Thus, capital not only refers to economic capital such as money and real estates, but to cultural capital (i.e., education, knowledge, skills) and social capital (i.e., relations, networks) as well. Within this two-dimensional space, traditionally used socio-economic variables define the "space of social position", whereas specific patterns of behaviour define the "space of lifestyles". Based on this, two hierarchies can be distinguished. One category reaches from the traditional lower status groups to the economic elites. Another category reaches from the same lower status groups to the cultural elites. Thus, various lifestyles only appear among social groups with high capital levels. The economic elites pursue material welfare and obtain rather traditional aesthetic and moral beliefs. The cultural elites display their knowledge, for example on contemporary art.

Ganzeboom (1988) elaborates further on the work of Bourdieu (1984) in order to analyze lifestyles in the Netherlands. Ganzeboom (1988) assumes that people symbolize and clarify their social position through a pattern of behaviours. This behaviour is determined by lifestyle. However, lifestyle indirectly influences behaviour through preferences. Based on their lifestyle, people have preferences on how to present themselves socially. These preferences are balanced against available opportunities and constraints, which results in the actual behaviour. In order to obtain a more precise definition, Ganzeboom (1988) discusses the origins and function of lifestyles. Lifestyle is related to the individual's socio-economic characteristics. However, this relationship is influenced by intermediate variables which refer to opportunities and constraints offered by time budget, income, cognitive skills (i.e., knowledge, skills) and status considerations (i.e., the influence of the social context, the aim to obtain social appreciation). Time budget and income can be measured objectively, whereas cognitive skills and status considerations are rather subjective. These four intermediate variables are internal to the individual. An additional, but external, intermediate variable consists of institutions (i.e., rules, regulations). Lifestyles must not be considered as unambiguous types. Ganzeboom (1988) stresses the existence of a continuum between lifestyle types rather than the occurrence of unambiguous lifestyle types. This continuum is determined by three dimensions: (i) an economic dimension, (ii) a cultural dimension, and (iii) a stage in life-dimension. The first two dimensions are inspired by Bourdieu (1984). However, Ganzeboom (1988) considers economic and cultural capital as two separate dimensions instead of the extremes of one dimension. The third dimension originates from Bourdieu's "space of social positions", which is based on traditionally used socio-economic variables. Ganzeboom (1988) distinguishes stable socio-economic background variables (e.g., gender) from changeable characteristics of stage in life (e.g., household composition, profession). He argues that some socio-economic variables have a dynamic nature and must, therefore, be treated differently. What resembles to be a free choice on a particular moment may restrict long-term choices. For example, educational choice may restrict further professional choices. As a result, an additional dimension, referring to stage in life, is added. This dimension operates in another way than the economic and cultural dimensions. No arguments can be put forward to consider one particular stage in life more important than another. In other words, no hierarchy can be found based on stage of life. Nevertheless, stage in life influences behaviour and preferences.

Weber (1972), Bourdieu (1984) and Ganzeboom (1988) agree on the communicative character of lifestyle: the individual elucidate his or her social position through specific 
patterns of behaviour. However, lifestyle includes more than observable patterns of behaviour. According to Ganzeboom (1988), lifestyle also refers to opinions and motivations, including beliefs, interests and attitudes. This may confound our understanding of the lifestyle concept. For that reason, Munters (1992) distinguished lifestyles from lifestyle expressions. He considered lifestyles as the individual's opinions and motivations, or orientations. Salomon and Ben-Akiva (1983) distinguished three fields of orientations: (i) family orientation, (ii) work orientation, and (iii) leisure orientation, whereas Bootsma et al. (1993) discerned five similar orientation fields: (i) household/family orientation, (ii) work orientation, (iii) housing orientation, (iv) consumption orientation, and (v) leisure orientation. Consequently, lifestyles are internal to the individual and, thus, are unobservable. A lifestyle, then, manifests itself in observable patterns of behaviour, or lifestyle expressions. In this way, observable patterns of behaviour (= lifestyle expressions) are explained by underlying opinions and orientations (= lifestyles). Location behaviour, activity behaviour and travel behaviour are some behavioural patterns in which lifestyles are expressed. For example, a family-oriented lifestyle manifest itself through living in a child-friendly residential neighbourhood, participating in family activities such as picking up the children from school and travelling by car rather than by public transport.

From the above, it should be clear how to measure lifestyles. Briefly summarized, lifestyle refers to the individual's opinions and orientations toward general themes such as family orientation, work orientation and leisure orientation. Some empirical studies (e.g., Hildebrand, 2003; Cooper et al., 2001; Salomon and Ben-Akiva, 1983) analyze what they would call lifestyles, but in fact they combine various objective socio-economic and demographic characteristics of the individual and the household. Consequently, these studies refer to stage of life cycle or household composition rather than to lifestyles. Although a lifestyle is partly influenced by stage of life cycle or household composition, lifestyle has a different meaning. Socio-economic and demographic variables are, therefore, separated from lifestyles by including them as opportunities and constraints at the individual and social level of our conceptual model (see Figure 1).

Recently, several empirical studies try to include the individual's lifestyle within travel behaviour research. Most studies (e.g., Collantes and Mokhtarian, 2007; Bagley and Mokhtarian, 2002; Lanzendorf, 2002; Redmond, 2000; Kitamura et al., 1997) confirm that the lifestyle concept adds explanatory power to travel analyses. Scheiner and Holz-Rau (2007) and Scheiner (2006) refined these conclusions. They remarked that lifestyles do influence activity and travel behaviour. Nevertheless, the influence of objective socio-economic and demographic characteristics exceeds the influence of subjective lifestyles.

\section{Why homogeneous groups behave differently}

The previously described decision hierarchy might come across as "physicalist", as considering only the observable locational, activity and travel behaviours and not the underlying individual's motivations and intentions. Although some general motivations and intentions are included in the decision hierarchy by the lifestyle concept, research indicates that individuals of socio-economic homogenous groups may still behave differently. This might be due to individual perceptions, attitudes and preferences toward location, activity and travel behaviour (van Wee, 2002; Mokhtarian and Cao, 2008). Perceptions refer to the way various aspects of the built environment, activities and travel are considered by an individual, whereas attitudes include an evaluation of these characteristics. Preferences are then formulated based on these attitudes and perceptions. This includes a ranking of different spatial, activity and travel opportunities. (Golledge and Stimson, 1997; Allaman and Tardiff, 1982). These specific subjective characteristics are different from the general one's that define 
lifestyle. Most empirical activity-based travel studies do not incorporate these factors. Some researchers argue that perceptions, attitudes and preferences are difficult to measure and, therefore, cannot be taken into account (e.g., Gärling et al., 1998; Borgers et al., 1997; Golledge and Stimson, 1997), whereas other researchers state the opposite (e.g., Collantes and Mokhtarian, 2007; Parkany et al., 2004; Lanzendorf, 2002; Bagley and Mokhtarian, 2002; Kitamura et al., 1997; Camstra, 1996).

Insights from theories in social psychology can help us to operationalize perceptions, attitudes and preferences. After all, social psychology focuses on how people think, feel and behave toward other people, and how these thoughts, feelings and behaviours may be influenced by other people (Brehn et al., 2005). For this reason, combining insights from social psychology and previously described concepts from transport geography seems auspicious. Moreover, certain theories in social psychology argue that behaviour is not always well-reasoned through perceptions, attitudes and preferences. Behaviour has, thus, a reasoned component as well as an unreasoned component. These two components underlie the decision hierarchy in our conceptual model of travel behaviour (see Figure 1).

\subsection{Reasoned behaviour}

The study of attitudes is a core topic in social psychology. Several definitions exists, but an attitude generally refers to a positive, negative or mixed evaluative response to some stimuli (issues, objects or persons) which influences the individual's behaviour (Brehn et al., 2005; Gärling et al., 1998). Triandis (1971) stresses three aspects of attitudes consist: (i) a cognitive aspect involving perceptions and knowledge of the stimuli, (ii) an affective aspect involving feelings, emotions and values, and (iii) a behavioural aspect involving acting in response to the two other aspects. As such attitudes bring together someone's internal mental life and behavioural responses within one framework (Gold, 1980). Attitudes have always been an important research subject in social psychology. Since the late 1920's, researchers have tried to measure attitudes (e.g., Thurnstone, 1928), which resulted in more than five hundred published measurement methods (Fishbein and Ajzen, 1972). Nevertheless, research indicates that the relationship between attitudes and behaviour is not perfect at all (e.g., Ajzen and Fishbein, 1977; LaPierre, 1934). Attitudes are not the only decisive factors of behaviour and, therefore, attitudes and behaviour must be treated within a broader context. This basic assumption is elaborated by Fishbein and Ajzen (1975) and Fishbein (1980) in the Theory of Reasoned Action. Ajzen (1991) has specified this theory into the Theory of Planned Behaviour.

In the Theory of Reasoned Action (TRA) behaviour is considered as the result of rational choices. People are considered as rational human beings. By categorizing, transforming and interpreting information on a stimulus (issue, object or person), an individual forms a perception about this stimulus (Golledge and Stimson, 1997). In the TRA this perception is called a belief. Several beliefs (or perceptions) are associated with one specific stimulus, because several attributes of this stimulus are evaluated. The sum of all related beliefs determines the attitude toward that stimulus. For example, an individual may perceive cycling as healthy, environment-friendly, etc. Because of these beliefs, the individual adopts a positive attitude toward cycling. However, this does not automatically results in a travel pattern characterized by more cycling trips. Attitudes do not directly influence behaviour. According to the TRA, intentions intervene in the relationship between attitudes and behaviour. The attitude toward a stimulus is considered as related to various intentions to behave with respect to that stimulus. For example, the individual's positive attitude toward cycling results in a set of intentions which, in their totality, are positive as well. This person may intend to commute by bicycle, to spend a cycling holiday, etc. Or in other words, that person will prefer the bicycle above all other travel modes. We argue that the concept of 
intentions is thus closely related to preferences. This is inspired by Golledge and Stimson (1997) who consider preference as an activity that expresses or identifies how an individual desires or intends to behave.

Intentions are influenced by attitudes as well as by other factors. The TRA also considers the subjective norm as a factor influencing the intention to behave in a particular way. The subjective norm is the sum of normative beliefs which refer to the perceived social pressure to perform or not perform a particular behaviour. The TRA is only suitable for behaviours which are under a person's volitional control. However, the theory is inappropriate to explain and predict uncontrollable behaviour. In order to overcome this problem, Ajzen (1991) developed the Theory of Planned Behaviour. This theory considers a third determinant of intention, namely perceived behavioural control which refers to the perceived ability to perform a behaviour. For example, despite a positive attitude toward cycling, an individual considers himself or herself physically unable to commute by bicycle. Therefore, this individual might intend to commute by car. Perceived behavioural control directly influences behaviour as well. For example, someone commutes by car because he or she thinks that no public transport services are available on the route toward work. However, perceived behavioural control might be inaccurate. Consequently, the theory distinguishes perceived behavioural control and actual behavioural control.

The foregoing explains how specific characteristics such as perceptions, attitudes and preferences are related to behaviour. Those characteristics account for consistent patterns of behaviour and, therefore, can be considered as a part of someone's personality (Pervin and John, 1997). For example, Baron and Byrne (1991) consider personality as "the combination of relatively enduring attitudes that are expressed consistently and predictably in various situations" (Redmond, 2000, p. 11). However, personality research does not focus on how characteristics such as attitudes are constructed, but rather on how individuals differ in those characteristics and how this influences their behaviours. Consequently, it provides limited insights in someone's behavioural reasoning and decision-making and for this reason the notion of personality is not mentioned in Figure 1.

\subsection{Unreasoned behaviour}

Nevertheless, the Theory of Reasoned Action and the Theory of Planned Behaviour remain subject to criticism. Both theories assume that behaviour results from rational decisions, but individuals are not constantly conscious of their behaviour (Pred, 1967; Simon, 1950). Triandis (1980, p. 204) mentions the influence of habits which he defined as "situationspecific sequences that are or have become automatic, so that they occur without selfinstruction”. Moreover, he suggested a trade-off between attitudes and habits in the prediction of behaviour (Triandis, 1977). If habits are strong, the attitude-behaviour relationship is weak, and vice versa. Empirical studies such as Bamberg et al. (2003) and Verplanken et al. (1994, 1998) confirmed this trade-off between habits and attitudes also exists in travel behaviour.

Ronis et al. (1989) formulated the Theory of Repeated Behaviour (TRB). Initial behaviour remains the result of relevant attitudes and beliefs. But once the behaviour is repeated, it becomes a habit and decision-making is no longer based on attitudes and other well-reasoned influences. Repeated behaviour is, therefore, assumed to be mainly influenced by habits rather than by attitudes. Thus, three main categories of variables directly influence behaviour: (i) unreasoned influences, (ii) resources or enabling variables, and (iii) reasoned influences. One could also consider the correspondence between the TRB and the concept of transaction costs in economics (Menard, 1997). For example, although car-users might be motivated to switch to other travel modes, habits prevent them from doing so. Switching to other travel modes necessitate learning new routines. In order to do so, someone has to search and process information about the alternative travel modes. The costs associated with this may exceed the 
additional benefit of a better decision so that behaviour is more a matter of habits or routines. Consequently, it is logical that behavioural decisions are not always well-reasoned (Gärling and Axhausen, 2003).

Recent advances in activity-based research account for unreasoned behaviour by studying activity scheduling and rescheduling processes (e.g., Zhou and Golledge, 2007; Lee and McNally, 2006; Doherty, 2005; Joh et al., 2004, 2005; Doherty and Miller, 2000). Activities are planned over varying time horizons. Activities such as working or shopping are weekly or daily recurrent activities. Planning such activities into a daily activity schedule is, thus, more a matter of routines or habits than of well-reasoned behaviour. These repeated activities (or habits) establish an initial skeleton schedule, in which well-reasoned decisions related to preplanned activities as well as impulsive decisions related to events-of-the-day activities are fit in. As a result, activity schedules consist of a reasoned and an unreasoned component.

\section{Interdependencies, opportunities and constraints}

Previous sections describe travel behaviour from the perspective of the individual. Despite recent advances, external factors such as the social environment and the spatial environment are generally ignored in studies on travel attitudes and habits. Nevertheless, accounting for the influence of the social environment and the spatial environment would help us clarifying the complex nature of travel behaviour. After all, the individual does not act within a "vacuous space". The individual is a member of a social network of family, friends and colleagues, lives within in a particular neighbourhood and travels to a specific destination. Consequently, the individual decision hierarchy and its underlying components must be considered within a social environment and a spatial environment (see Figure 1). A theoretical explanation of the influence of the social environment can be found in social cognitive theory. Ecological and environmental psychology provides a theoretical framework for the influence of the spatial environment.

\subsection{Interdependencies due to the social environment}

Social cognitive theory (Bandura, 1986) considers reciprocal relationships between behaviour, personal characteristics, and the environment. Within the social cognitive theory, the environment mainly refers to the individual's social environment of which the household is the most important one. These three factors all operate as interacting determinants of each other. The reciprocal relationships are not perfect symmetrical: relationships may differ in strength and may occur on different points in time. Because of this aspect, it is possible to decompose the triadic reciprocity. Thus, studies are able to focus on some (segments of) bidirectional relationships without having to consider the whole model.

The social dimension of travel has been ignored for a long time (Axhausen, 2005). Only recently, some activity-based travel studies analyze the link between the individual's travel behaviour and their social network (e.g, Artenze and Timmermans, 2008; Dugundji and Gulyás, 2008; Schwanen, 2008b; Paéz and Scott, 2007; Carrasco and Miller, 2006; Dugundji and Walker, 2005; Miller and Roorda, 2003). These studies assume that travel behaviour cannot be understood solely by individual characteristics such as age, gender or income. One must also consider social network characteristics emerging from the interaction among social network members such as network composition and physical distance between network members. The results indicate that measures of the individuals' social networks can provide insights about travel behaviour.

Previously described studies generally focus on the objectively quantifiable characteristics of the social network, which corresponds with the notion of "environment" in social cognitive theory. However, this theory also stresses the influence of the "situation" which refers to the 
person's perception of the objective environment. For example, empirical travel studies indicate that the presence of young children in the household influences the parents' travel behaviour. This relationship can be measured by an objective variable such as "the number of children aged below 6 years" or by a subjective variable referring to the parents' attitude toward having and raising children.

\subsection{Interdependencies due to the spatial context}

Whereas social cognitive theory focuses on the social environment, ecological psychology and environmental psychology stress the influence of the spatial environment. However, ecological psychology and environmental psychology have another scope. Ecological psychology studies collective processes by which groups adapt themselves to spatial and social characteristics of the environment, whereas environmental psychology analyzes the micro level, namely intrapersonal processes such as perception, cognition and learning behaviour, which influence the relationship between environment and behaviour (Stokols, 1977). Since individual decisions (and not group processes) are at the centre stage of our conceptual model, mainly insights from environmental psychology (and not ecological psychology so much) may contribute to our discussion.

Environmental psychology questions the role of basic psychological intrapersonal processes, such as perception and cognition, in mediating the relationship between human behaviour and the environment. Intrapersonal processes such as perception indicate that behaviour is not only influenced by objective characteristics of the environment, but by the subjective evaluation of these characteristics as well (Stokols, 1977). For example, in his famous work The Image of the City, Lynch (1960) described how individuals perceive the spatial environment in terms of paths, edges, districts, nodes and landmarks. This also relates to the issue of spatial cognition which can be defined as "the knowledge and internal or cognitive representation of the structure, entities and relations of space; in other words, the internalized reflection and reconstruction of space and thought” (Hart and Moore, 1973, p. 248). By the mid 1960s geographers adopted the idea of spatial cognition and they represented how spatial information is perceived in some map like form, so-called mental maps (Golledge and Stimson, 1997). An individual selects, organizes and puts a meaning to a limited number of features in the environment. These features are the focal points around which the individual constructs his or her mental map of the environment (Golledge and Zannaras, 1973). Research indicates that those internal models of the environment or mental maps influence our daily travel behaviour (e.g., Chorus and Timmermans, 2009; Dziekan, 2008; Mondschein et al., 2006; Arentze and Timmermans, 2005). As such, the spatial environment in our conceptual model resembles objective as well as subjective characteristics of the wider environment in which daily travel behaviour occurs. This environment does not necessarily coincide with locational decisions discussed earlier.

Although ecological psychology and environmental psychology have different scopes, they converged toward each other. Behaviour is, thus, considered as the result of internal and subjective (personal) and external and objective (situational) characteristics. This was already noted by Lewin (1936) who stated:

$$
B=f(I P, E D)
$$

where: $\mathrm{B}=$ behaviour

IP = subjective intrapersonal processes (physiological and psychological)

$\mathrm{ED}=$ objective environmental dimensions (physical, social and cultural)

Consequently, current environmental-behavioural research examines various categories of antecedents of behaviour. Moreover, environmental-behavioural research must deal with 
multiple levels of analysis, ranging from micro, intermediate to macro levels. The micro level refers to the individual and intrapersonal processes which affect the influence of the direct environment on the individual behaviour. The intermediate level refers to the social environment and interpersonal processes, i.e. individual and small-group behaviours, in a specific behaviour setting and institutional environment. Finally, the macro level refers to the community level of influence in the context of large-scale environmental units such as neighbourhoods and cities (Handy, 2005; Stokols, 1977). These interdependencies are symbolized by a multilevel structure in our conceptual model (see Figure 1). More specifically, the individual level is embedded in a social level and a spatial level.

\subsection{Individual, social and spatial opportunities and constraints}

The central box in our conceptual model refers to how the individual's reasoning determines travel behaviour. Habits as well as subjective characteristics, such as perceptions and attitudes, are important factors. Nevertheless, because of a lack of appropriate data most empirical studies on travel behaviour include objective characteristics instead of subjective factors. After all, objective characteristics of the individual, the social environment and the spatial environment might facilitate or constrain travel behaviour (for a review, see van Wee, 2002; Ewing and Cervero, 2001). For example, car use will be higher for individuals with a driving license, for households owning several cars and in suburban neighbourhoods. Therefore, the central box is also influenced by objective characteristics at each level of the conceptual model (see Figure 1).

\section{Discussion: conceptual and modelling implications}

Key-variables in research on the link between the built environment and travel behaviour generally refer to three components: (i) a spatial component, (ii) a socio-economic component, and (iii) a personality component. Theories in transport geography justify the incorporation of a spatial component (and even a spatiotemporal component) and a socioeconomic component, whereas theories in social psychology validate the incorporation of a personality component. Our conceptual model of travel behaviour explicitly combines the three components. Various concepts and findings from the reviewed theories are included within our conceptual model of travel behaviour which is visualized in Figure 1.

Firstly, we consider travel behaviour as derived from short-term activity decisions, medium-term location decisions and long-term lifestyle decisions. This decision hierarchy is inspired by principles of the activity-based approach and lifestyle theory. By considering the derived nature of travel behaviour, behavioural insights in travel patterns are obtained which were previously lacking in the frequently used trip-based models.

Secondly, behavioural decisions are regarded as the result of an assessment between reasoned and unreasoned influences. Following the Theory of Repeated Behaviour (Ronis et al., 1989) initial behaviour depends more on reasoned influences, whereas unreasoned influences will determine repeated behaviour to a greater extent. In fact, studies such as Bamberg et al. (2003) and Verplanken et al. $(1994,1998)$ confirmed a trade-off between travel attitudes and travel habits. Although we are aware of a link between reasoned and unreasoned influences, it is not represented in Figure 1. This is only because the conceptual model focuses on explaining individual daily travel behaviour, and not on the trade-off between reasoned and unreasoned influences. We also argue that these reasoned and unreasoned influences on their turn are affected by the individual's lifestyle. This is partly based on Ganzeboom (1988) who presumed that lifestyles influence preferences. We also consider the link between lifestyles and unreasoned influences. After all, it is possible that certain lifestyles are associated with more unreasoned behaviour than other lifestyles. For 
example, an adventurous lifestyle permits less well-reasoned behaviour and more unreasoned behaviour than a family-oriented lifestyle.

The conceptual model as described above focuses on travel behaviour of the individual. However, the individual belongs to a social network of family, friends and colleagues and lives within a particular neighbourhood which can affect the individual's behaviour. So finally, the model as a whole should be placed within (i) an individual level, (ii) the social environment, and (iii) the spatial environment. Empirical studies generally use objective variables that refer to characteristics of each level or environment. For example, the spatial environment is defined in terms of density, diversity and design. These objective variables are however perceived and evaluated by individuals with specific lifestyles so that studies such as Schwanen and Mokhtarian (2005a), van Wee et al. (2002) and Koppelman and Pas (1980) also used more subjective variables. Nevertheless, almost none of these studies questions whether perceptions correspond to the objective reality. For example, a neighbourhood is objectively evaluated as pedestrian friendly (e.g., low motorized traffic levels, availability of sidewalks), but an individual with a specific lifestyle might still consider this neighbourhood as unsafe (Handy, 1996). Therefore, it would be interesting to assess objective variables with more subjective variables.

The dotted arrows in Figure 1 refer to feedback mechanisms: individuals can learn from previous experiences. Consequently, lifestyles, habits, perceptions, attitudes and preferences are not fixed in time.

Figure 1: A conceptual model of travel behaviour

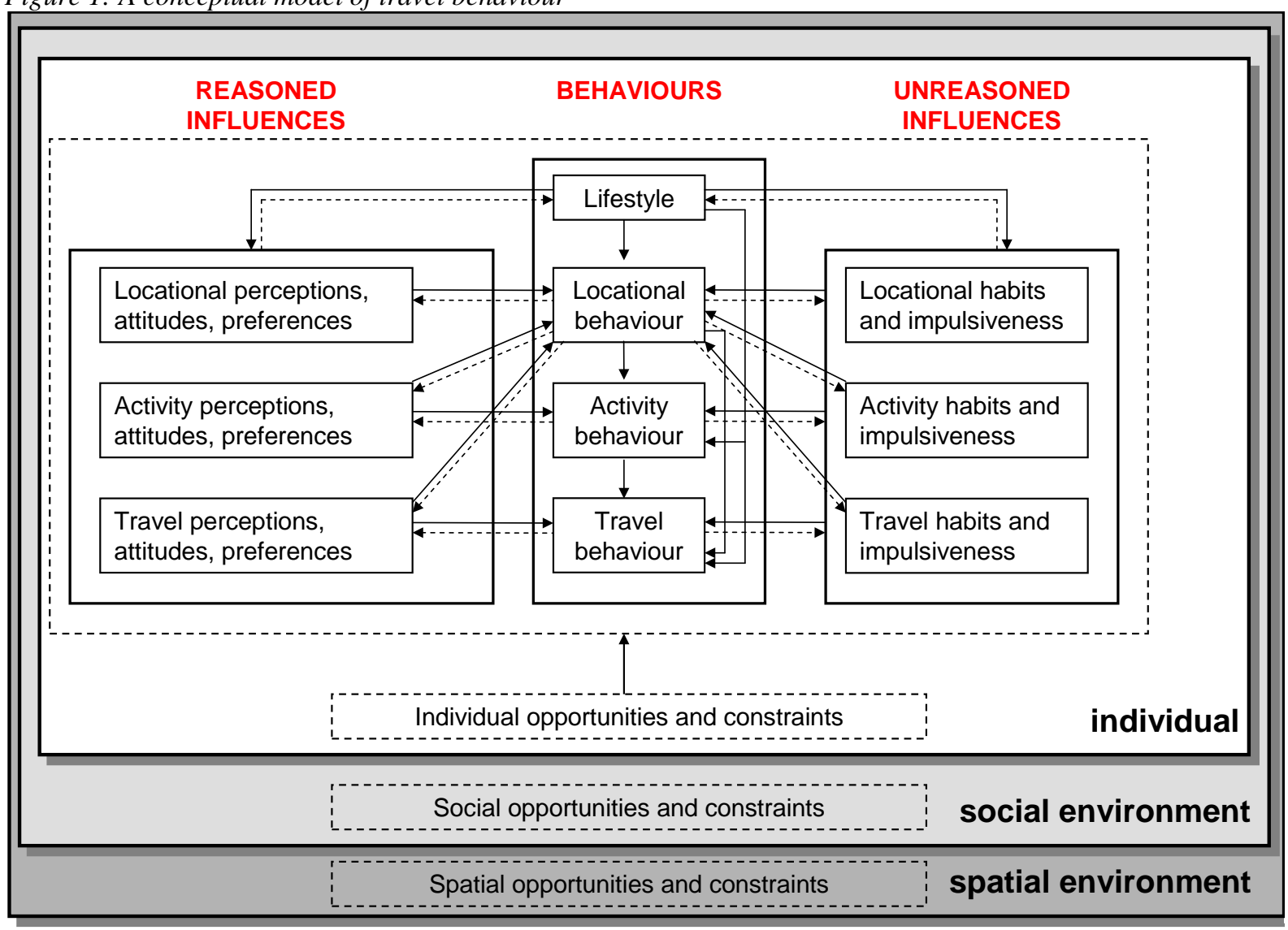

Putting the conceptual model into practice involves collecting appropriate data and using a suitable modelling technique. Depending on the research focus, different modelling approaches can be undertaken. Our conceptual model includes numerous relationships, 
resulting in direct and indirect effects on travel behaviour. This kind of interdependency can be analyzed using structural equation models (SEM) (e.g., Van Acker et al., 2007; Simma and Axhausen, 2003; Bagley and Mokhtarian, 2002). A second kind of interdependencies results from a nested data structure: individuals are nested within households, and households within neighbourhoods. This nested data structure is best analyzed using a multilevel analysis. Multilevel analysis can be combined with a SEM so that both kinds of interdependencies are accounted for and the complexity of travel behaviour is better understood (e.g., Chung et al., 2004; Kim et al., 2004).

A (multilevel) SEM is represented by a series of simultaneously estimated equations. This implies that all components of the conceptual model in Figure 1 are concurrently and continually considered. However, we also argued that components such as attitudes evolve over time and that decisions on various time scales influence each other. In order to study the dynamics between several components of the conceptual model, a sequential approach such as event history analysis seems more appropriate (e.g., Beige and Axhausen, 2008; Scheiner, 2006; Verhoeven et al., 2005). This approach needs a longitudinal perspective, for example by conducting a panel survey or a retrospective survey.

We expect that an analysis of the relationships outlined in our conceptual model by one of the suggested approaches will enrich the research debate on travel behaviour with constructive insights.

\section{Conclusion}

For several decades researchers try to measure the influence of the built environment on travel behaviour. Empirical studies use three kinds of variables referring to a spatial component (e.g., density, diversity, and design), a socio-economic component (e.g., age, gender, education, income) and a personality component (e.g., lifestyle, attitudes). However, these studies lack a theoretical justification of why travel behaviour should be influenced by these three components after all. Such theoretical justification can, however, be found when theories from transport geography are combined with theories in social psychology and lifestyle theory.

Theories in transport geography justify the influence of factors external to the individual on travel behaviour. In other words, it describes the context in which travel behaviour is performed. More specifically, time geography stresses a spatiotemporal component of travel and the activity-based approach considers travel behaviour as derived from activity patterns.

The influence of factors internal to the individual is validated by theories in social psychology. These theories describe the influence of internal processes including reasoned influences such as perceptions, attitudes and preferences, and unreasoned influences such as habits.

In our conceptual model, we combine both theoretical fields: daily travel behaviour is embedded in a decision hierarchy and these behavioural decisions are the result of an assessment of reasoned and unreasoned influences. Moreover, individual decision-making and behaviour should be considered within a social environment and spatial environment. Those environments include processes and characteristics external to the individual that can influence individual behaviour.

Putting the conceptual model into practice involves collecting appropriate data and using a suitable modelling technique. Depending on the type of research data (cross-sectional versus longitudinal data) and the research focus (e.g., disentangling the complexity between various components of the conceptual model versus analyzing the evolution over time of these components), (multilevel) SEM and event history analysis seem to be appropriate and 
interesting modelling techniques. Empirical studies that combine the relationships of our conceptual model could make a major contribution to the research debate on travel behaviour.

\section{Acknowledgment}

We would like to thank the three anonymous reviewers of this paper for their valuable comments.

\section{References}

Ajzen, I. (1991) The theory of planned behaviour, Organizational Behavior and Human Decision Processes, 50, pp. 179-211.

Ajzen, I. and Fishbein, M. (1977) Attitude-behavior relations: A theoretical analysis and review of empirical research, Psychological Bulletin, 84, pp. 888-918.

Algers, S., Eliasson, J. and Mattsson, L.G. (2005) Is it time to use activity-based urban transport models? A discussion of planning needs and modelling possibilities, Annals of Regional Science 39, pp. 767-789.

Allaman, P.M. and Tardiff, T.J. (1982) Structural models of attitude-behavior relations for intercity rail travelers, Transportation Research Record, 894, pp. 48-55.

Arentze, T.A. and Timmermans, H.J.P. (2008) Social network, social interaction, and activitytravel behavior: A framework for microsimulation, Environment and Planning B, 35, pp. 1012-1027.

Arentze, T.A. and Timmermans, H.J.P. (2005) Representing mental maps and cognitive learning in micro-simulation models of activity-travel choice dynamics, Transportation, 32, pp. 321-340.

Axhausen, K.W. (2005) Social networks and travel: Some hypotheses, in: Donaghy, K., Poppelreuter, S. and Rudinger, G. (Eds.) Social Dimensions of Sustainable Transport: Transatlantic Perspectives, pp. 90-108 (Aldershot: Ashgate).

Axhausen, K.W. and Gärling, T. (1992) Activity-based approaches to travel analysis: Conceptual frameworks, models and research problems, Transport Reviews, 12, pp. 324341.

Bagley, M.N. and Mokhtarian, P.L. (2002) The impact of residential neighborhood type on travel behavior: A structural equation modeling approach, Annals of Regional Science, 36, pp. 279-297.

Bamberg, S., Rölle, D. and Weber, C. (2003) Does habitual car use not lead to more resistance to change of travel mode ?, Transportation, 30, pp. 97-108.

Bandura, A. (1986) Social Foundations of Thought and Action: A Social Cognitive Theory (New Jersey: Prentice-Hall).

Baron, R.A. and Byrne, D. (1991) Social Psychology: Understanding Human Interactions (Needham Heights: Allyn \& Bacon).

Beige, S. and Axhausen, K.W. (2008) Long-term and mid-term mobility decision during the life course, Journal of International Association of Traffic and Safety Sciences, 32, pp. 1633.

Ben-Akiva, M. (1973) Structure of Passenger Travel Demand Models. PhD dissertation, Department of Civil Engineering, MIT, Cambrigde, MA.

Bhat, C.R. and Guo, J.Y. (2007) A comprehensive analysis of built environment characteristics on household residential choice and auto ownership levels, Transportation Research B, 41, pp. 506-526. 
Bhat, C.R. and Koppelman, F.S. (1999a) Activity-based modeling of travel demand, in: Hall, R.W. (Ed.) Handbook of Transportation Science, pp. 39-65 (Norwell: Kluwer Academic Publishers).

Bhat, C.R. and Koppelman, F.S. (1999b) A retrospective and prospective survey of time-use research, Transportation, 26, pp. 119-139.

Boarnet, M. and Crane, R. (2001) The influence of land use on travel behavior: Specification and estimation strategies, Transportation Research A, 35, pp. 823-845.

Bootsma, H., Camstra, R., de Feijter, H. and Mol, A. (1993) Leefstijl: een dynamische levensorientatie, Rooilijn, 26, pp. 332-337. [in Ducth]

Borgers, A.W.J., Hofman, F. and Timmermans, H.J.P. (1997) Activity-based modelling: prospects, in: Ettema, D.F. and Timmermans, H.J.P. (Eds.) Activity-Based Approaches to Travel Analysis, pp. 339-352 (Oxford: Elsevier).

Bourdieu, P. (1984) La Distinction (London: Routledge).

Brehn, S.S., Kassin, S.M. and Fein, S. (2005) Social Psychology (Boston: Houghton Mifflin Company).

Buliung, R.N. and Kanarogloy, P.S. (2007) Activity-travel behaviour research: Conceptual issues, state of the art, and emerging perspectives on behavioural analysis and simulation modelling, Transport Reviews, 27, pp. 151-187.

Camstra, R. (1996) Commuting and gender in a lifestyle perspective, Urban Studies, 33, pp. 283-300.

Cao, X., Mokhtarian, P.L. and Handy, S.L. (2007a) Do changes in neighborhood characteristics lead to changes in travel behavior ? A structural equations modeling approach, Transportation, 34, pp. 535-556.

Cao, X., Mokhtarian, P.L. and Handy, S.L. (2007b) Cross-sectional and quasi-panel explorations of the connection between the built environment and auto ownership, Environment and Planning A, 39, pp. 830-847.

Carrasco, J.A. and Miller, E.J. (2006) Exploring the propensity to perform social activities: A social network approach, Transportation, 33, pp. 463-480.

Chapin, F.S. Jr. (1974) Human Activity Patterns in the City: What do People do in Time and Space (Toronto: John Wiley).

Chen, C., Gong, H.M. and Paaswell, R. (2008) Role of the built environment on mode choice decisions: additional evidence on the impact of density, Transportation, 35, pp. 285-299.

Chorus, C. and Timmermans, H. (2009). Empirical study into influence of travel behavior on stated and revealed mental maps. Proceedings of the Transportation Research Board $88^{\text {th }}$ Annual Meeting, Washington D.C.

Chung, J.-H., Kim, S., Lee, Y.-K. and Choi, Y.-S. (2004) Multilevel structural equation model for activity participation and travel behaviour. Data from the Puget Sound Transportation Panel, Transportation Research Record, 1898, pp. 52-60.

Clark, W.A.V., Huang, Y.Q. and Withers, S. (2003) Does commuting distance matter ? Commuting tolerance and residential change, Regional Science and Urban Economics, 33, pp. 199-221.

Collantes, G.O. and Mokharian, P.L. (2007) Subjective assessments of personal mobility: What makes the difference between a little and a lot ?, Transport Policy, 14, pp. 181-192.

Cooper, J., Ryley, T. and Smith, A. (2001) Contemporary lifestyles and the implications for sustainable development policy: lessons from the UK's most car dependent city; Belfast, Cities, 18, pp. 103-113.

Crane, R. (1996) On form versus function: Will the New Urbanism reduce traffic, or increase it? Journal of Planning Education and Research, 15, pp. 117-126. 
Cullen, I.G. (1978) The treatment of time in the explanation of spatial behaviour, in: Carlstein, T., Parkes, D. and Thrift, N. (Eds.) Human Activity and Time Geography, pp. 27-38 (London: Edward Arnold).

Cullen, I.G. and Godson, V. (1975) Urban Networks: The Structure of Activity Patterns, Progress in Planning, 4, pp. 1-96.

Doherty, S.T. (2005) How far in advance are activities planned ? Measurement challenges and analysis, Transportation Research Record, 1926, pp. 41-49.

Doherty, S. T. and Miller, E.J. (2000) A computerized household activity scheduling survey, Transportation, 27, pp. 5-23.

Dziekan, K. (2008) What do people know abut their public transport options ?, Transportation, 35, pp. 519-538.

Dugundji, E. and Gulyás, L. (2008) Sociodynamic discrete choice on networks in space: Impacts of agent heterogeneity on emergent outcomes, Environment and Planning B, 35, pp. 1028-1054.

Dugundji, E. and Walker, J. (2005) Discrete choice with social and spatial network interdependencies. An empirical example using Mixed GEV models with field and "panel" effects, Transportation Research Records, 1921, pp. 70-78.

Ettema, D. and Timmermans, H. (1997) Theories and models of activity patterns, in: Ettema, D. and Timmermans, H. (Eds.) Activity-Based Approaches to Travel Analysis, pp. 1-36 (Oxford: Pergamon).

Ewing, R. and Cervero, R. (2001) Travel and the built environment: a synthesis, Transportation Research Record, 1780, pp. 87-114.

Ferge, S. (1972) Social differentiation in leisure activity choices, in: Szalai, A. (Ed.) The Use of Time: Daily Activities of Urban and Suburban Population in Twelve Countries, pp. 213227 (Den Haag: Mouton).

Fishbein, M. (1980) A theory of reasoned action: Some applications and implications, in: Horve, H. Jr. (Ed.) Nebraska Symposium on Motivation, pp. 65-116 (Lincoln: University of Nebraska Press).

Fishbein, M. and Ajzen, I. (1972) Attitudes and opinions, Annual Review of Psychology, 23, pp. 487-544.

Frandberg, L. (2008) Paths in transnational time-space: Representing mobility biographies of young Swedes, Geografiska Annaler B - Human Geography, 90B, pp. 17-28.

Fried, M., Havens, J. and Thall, M. (1977) Travel behavior - A synthesized theory (Boston: Boston College).

Ganzeboom, H. (1988) Leefstijlen in Nederland: Een Verkennende Studie (Rijswijk: Sociaal Cultureel Planbureau). [in Dutch]

Gardner, B. (2009) Modelling motivation and habit in stable travel mode contexts, Transportation Research F, 12, pp. 68-76

Gärling, T. and Axhausen, K.W. (2003) Introduction: Habitual travel choice, Transportation, 30, pp. 1-11.

Gärling, T., Gillhom, R. and Gärling, A. (1998) Reintroducing attitude theory in travel behaviour research. The validity of an interactive interview procedure to predict car use, Transportation, 25, pp. 129-146.

Gliebe, J.P. and Koppleman, F.S. (2005) Modeling household activity-travel interactions as parallel constrained choices, Transportation, 32, pp. 449-471.

Golledge, R.G. and Stimson, R.J. (1997) Spatial Behavior: A Geographic Perspective (New York: The Guildford Press).

Golledge, R.G. and Zanaras, G. (1973) Cognitive approaches to the analysis of human spatial behavior, in: Ittelson, W.H. (Ed.) Environment and Cognition, pp. 59-94 (New York: Seminar Press). 
Gold, J.R. (1980) An Introduction to Behavioural Geography (New York: Oxford University Press).

Hägerstrand, T. (1970) What about people in regional science ?, Papers of the Regional Science Association, 24, pp. 7-21.

Handy, S. (2005) Critical Assessment of the Literature on the Relationships among Transportation, Land Use and Physical Activity (Washington: Transportation Research Board).

Handy, S.L. (1996) Urban form and pedestrian choices: Study of Austin neighbourhoods, Transportation Research Record, 1552, pp. 135-144.

Hanson, S. and Schwab, M. (1986) Describing disaggregate flows: Individual and household activity patterns, in: Hanson, S. (Ed.) The Geography of Urban Transportation, pp. 166187 (New York: The Guildford Press).

Hart, R.A. and Moore, G.T. (1973) The development of spatial cognition: A review, in: Downs R.M. and Stea, D. (Eds.) Image and Environment: Cognitive Mapping and Spatial Behavior, pp. 246-288 (Chicago: Aldine).

Hildebrand, E.D. (2003) Dimensions in elderly travel behaviour: A simplified activity-based model using lifestyle clusters, Transportation, 30, pp. 285-306.

Joh, C.H., Arentze, T. and Timmermans, H. (2004) Activity-travel scheduling and rescheduling decision processes. Empirical estimation of Aurora model, Transportation Research Record, 1898, pp. 10-18.

Joh, C.H., Doherty, T. and Polak, J.W. (2005) Analysis of factors affecting the frequency and type of activity schedule modification, Transportation Research Record, 1926, pp. 19-25.

Jones, P.M., Koppelman, F.S. and Orfeuil, J.P. (1990) Activity analysis: state of the art and future directions, in: Jones, P. (Ed.) Developments in Dynamic and Activity-Based Approaches to Travel Analysis, pp. 34-55 (Aldershot: Gower).

Kim, H.J., Kim, D.H. and Chung, J.-H. (2004) Weekend activity and travel behavior in a developing country. Empirical study using multilevel structural equation models, Transportation Research Record, 1894, pp. 99-108.

Kitamura, R., P.L. Mokhtarian \& L. Laidet (1997), A micro-analysis of land use and travel in five neighborhoods in the San Francisco Bay Area. Transportation 24, pp. 125-158.

Kitamura, R., Yamamoto, T., Susilo, Y.O. and Axhausen, K.W. (2006) How routine is a routine ? An analysis of the day-to-day variability in prism vertex location, Transportation Research A, 40, pp. 259-279.

Koppelman, F.S. and Pas, P.E. (1980) Travel-choice behavior: Models of perceptions, feelings, preference and choice, Transportation Research Record, 765, pp. 24-33.

Lanzendorf, M. (2002) Mobility styles and travel behavior: Application of a lifestyle approach to leisure travel, Transportation Research Record, 1807, pp. 163-173.

LaPierre, R.T. (1934) Attitudes vs. action, Social Forces, 13, pp. 230-237

Lee, M. and McNally, M.G. (2006) An empirical investigation on the dynamic processes of activity scheduling and trip chaining, Transportation, 33, pp. 553-565.

Lenntrop, B. (1976) Path in Space-Time Environments: A Time-Geographic Study of the Movement Possibilities of Individuals, Lund Studies in Geography, series B, 44.

Levinson, D.M. (1997) Jobs and housing tenure and the journey to work, Annals of Regional Science, 31, pp. 451-471.

Lewin, K. (1936) Principles of Topological Psychology (New York: McGraw-Hill).

Lynch, K. (1960) The Image of the City (Cambridge, MA: Technology Press).

McNally, M.G. (2000) The activity-based approach, in: Hensher, D.A. and Button, K.J. (Eds.)

Handbook of Transport Modeling, pp. 53-69 (Oxford: Pergamon).

Menard, C. (1997) Transaction Cost Economics: Recent Developments (Cheltenham: Elgar). 
Miller, H.J. (1991) Modeling accessibility using space-time prism concepts within Geographical Information Systems, International Journal of Geographical Information Systems, 5, pp. 287-301.

Miller, E.J. and Roorda, M. (2003) A prototype model of household activity/travel scheduling, Transportation Research Records, 1831, pp. 114-121.

Mitchell, A. (1983) The Nine American Lifestyles (New York: Warner).

Mokhtarian, P.L. and Cao, X.Y. (2008) Examining the impacts of residential self-selection on travel behaviour: A focus on methodologies, Transportation Research B, 42, pp. 204-228.

Mokhtarian, P.L. and Salomon, I. (2001) How derived is the demand for travel? Some conceptual and measurement considerations, Transportation Research A, 35, pp. 695-719.

Mokhtarian, P.L, Salomon, I. and Redmond, L.S. (2001) Understanding the demand for travel: It's not purely "derived”, Innovation: The European Journal of Social Science Research, 14, pp. 355-380.

Mondschein, A., Blumenberg, E. and Taylor, B.D. (2006) Cognitive mapping, travel behavior, and access to opportunity, Transportation Research Record, 1985, pp. 266-272.

Munters, Q.J. (1992) Bestaan leefstijlen (nog) wel ?, Sociologische Gids, 39, pp. 179-185. [in Dutch]

Neutens, T., Schwanen, T., Witlox F. and De Maeyer, Ph. (2008) My space or your space ? Towards a measure of joint accessibility, Computers, Environment and Urban Systems (forthcoming).

Neutens, T., Witlox, F., Van De Weghe, N. and De Maeyer, Ph. (2007a) Space-time opportunities for multiple agents: A constraint-based approach, International Journal of Geographical Information Science, 21, pp. 1061-1076.

Neutens, T., Witlox, F., Van De Weghe, N. and De Maeyer, Ph. (2007b) Human interaction spaces under uncertainty, Transportation Research Record, 2021, pp. 28-35.

Páez, A. and Scott, D.M. (2007) Social influence on travel behavior: A simulation example of the decision to telecommute, Environment and Planning A, 39, pp. 647-665.

Parkany, E., Gallagher, R. and Viveiros, P. (2004). Are attitudes important in travel choice ?, Transportation Research Record, 1984, pp. 127-139.

Pas, E.I. (1980) Toward the understanding of urban travel behavior through the classification of daily urban travel/activity patterns (Evanston: Northwestern University).

Pervin, L.A. and John, O.P. (1997) Personality Theory and Research (New York: John Wiley \& Sons)

Pinjari, A.R., Pendyala, R.M., Bhat, C.M. and Waddell, P.A. (2007) Modeling residential sorting effects to understand the impact of the built environment on commute mode choice, Transportation, 34, pp. 557-573.

Pred, A. (1967) Behavior and Location: Foundations for a Geographic and Dynamic Location Theory. Part I (Lund: The Royal University of Lund).

Prillwitz, J., Harms, S. and Lanzendorf, M. (2007) Interactions between residential relocations, life course events, and daily commute distances, Transportation Research Record, 2021, pp. 64-69.

Redmond, L. (2000) Identifying and analyzing travel-related attitudinal, personality and lifestyle clusters in the San Francisco Bay Area (Davis, University of California - Davis).

Ronis, D.L., Yates, J.F. and Kirscht, J.P. (1989) Attitudes, decisions, and habits as determinants of repeated behaviour, in: Pratkanis, A.R., Breckler, S.J. and Greenwald, A.G. (Eds.) Attitude Structure and Function, pp. 213-239 (Hillsdale: Lawrence Erlbaum Associates).

Salomon, I. (1981) Life style as a factor in explaining travel behavior ( $\mathrm{PhD}$ thesis, Massachusettes Institute of Technology). 
Salomon, I. and Ben-Akiva, M. (1983) The use of the life-style concept in travel demand models, Environment and Planning, A 15, pp. 623-638.

Scheiner, J. (2007) Mobility biographies: Elements of a biographical theory of travel demand, Erdkunde, 61, pp. 161-173.

Scheiner, J. (2006) Housing mobility and travel behaviour: A process-oriented approach to spatial mobility - Evidence from a new research field in Germany, Journal of Transport Geography, 14, pp. 287-298.

Scheiner, J. and Holz-Rau, C. (2007) Travel mode choice: affected by objective or subjective determinants ?, Transportation, 34, pp. 487-511.

Schlich, R. and Axhausen, K.W. (2003) Habitual travel behaviour: Evidence from a six-week travel diary, Transportation, 30, pp. 13-36.

Schwanen, T. (2008a) Struggling with time: Investigating coupling constraints, Transport reviews, 28, pp. 337-356.

Schwanen, T. (2008b) Managing uncertain arrival times through sociomaterial associations, Environment and Planning B, 35, pp. 997-1011.

Schwanen, T. (2007) Gender differences in chauffeuring children among dual-earner families, Professional Geographer, 59, pp. 447-462.

Schwanen, T., Ettema, D. and Timmermans, H. (2007) If you pick up the children, I'll do the groceries: spatial differences in between-partner interactions in out-of-home household activities, Environment and Planning A, 39, pp. 2754-2773.

Schwanen, T. and Mokhtarian, P.L. (2005a) What affects commute mode choice: neighborhood physical structure or preferences toward neighborhoods ?, Journal of Transport Geography, 13, pp. 83-99.

Schwanen, T. and Mokhtarian, P.L. (2005b) What if you live in the wrong neighborhood ? The impact of residential neighborhood type dissonance on distance traveled, Transportation Research D, 10, pp. 127-151.

Scott, D.M. and Kanaroglou, P.S. (2002) An activity-episode generation model that captures interactions between household heads: Development and empirical analysis, Transportation Research B: Methodological, 36, pp. 875-896.

Simma, A. and Axhausen, K.W. (2003) Interactions between travel behaviour, accessibility and personal characteristics: the case of Upper Austria, European Journal on Transport Infrastructure and Research, 3(2), pp. 179-197.

Simon, H. (1950) Modern organization theories, Advanced Management, 15, pp. 2-4.

Sobel, M.E. (1983) Lifestyle and social structure; concepts, definitions, analysis (New York: Academic Press).

Srinivasan, S. and Bhat, C.R. (2005) Modeling household interactions in daily in-home and out-of-home maintenance activity participation, Transportation, 32, pp. 523-544.

Srinivasan, S. and Bhat, C.R. (2008) An exploratory analysis of joint-activity participation characteristics using the American time use survey, Transportation, 35, pp. 301-327.

Stokols, D. (1977) Origins and directions of environment-behavioral research, in: Stokols, D. (Ed.) Perspectives on Environment and Behavior. Theory, Research and Applications, pp. 5-36 (New York: Plenum Press).

Susilo, Y.O. and Kitamura, R. (2005) Analysis of day-to-day variability in an individual's action space - Exploration of 6-week mobidrive travel diary data, Transportation Research Record, 1902, pp. 124-133.

Talvitie, A. (1997) Things planners believe in, and things they deny, Transportation, 24, 1-31.

Thurnstone, L.L. (1928) Attitudes can be measured, American Journal of Sociology, 33, pp. 529-544. 
Triandis, H.C. (1980) Values, attitudes and interpersonal behaviour, in: Howe, H.E. Jr. and Page, M.M. (Eds.) Nebraska Symposium on Motivation, pp. 195-260 (Lincoln: University of Nebraska Press).

Triandis, H. C. (1977) Interpersonal behavior (Monterey, CA: Brooks/Cole Publishing Company).

Triandis, H.C. (1971) Attitude and Attitude Change (New York: John Wiley \& Sons).

Van Acker, V., Witlox, F. and van Wee, B. (2007) The effects of the land use system on travel behaviour: A structural equation modelling approach, Transportation Planning and Technology, 30, pp. 331-354.

Van Wee B. (2002) Land use and transport: Research and policy challenges, Journal of Transport Geography, 10, pp. 259-271

Van Wee, B., Holwerda, H. and van Baren, R. (2002) Preferences for modes, residential location and travel behaviour: The relevance for land-use impacts on mobility, European Journal of Transport Infrastructure and Research, 2, pp. 305-316.

Verhoeven, M., Arentze, T., Timmermans, H.J.P. and van der Waerden, P. (2005) Modeling the impact of key events on long-term transportation mode choice decisions: Decision network approach using event history data, Transportation Research Record, 1926, pp. 106-114.

Verplanken, B., Aarts, H., van Knippenberg, A. and van Knippenberg, C. (1994) Attitude versus general habit - Antecedents of travel mode choice, Journal of Applied Social Psychology, 24, pp. 285-300.

Verplanken, B., Aarts, H., van Knippenberg, A. and Moonen, A. (1998) Habit versus planned behaviour: A field experiment, British Journal of Social Psychology, 37, pp. 111-128.

Voysha, P., Petersen, E. and Donnelly, R. (2004) Impact of intrahousehold interactions on individual daily activity/travel patterns, Transportation Research Record, 1898, pp. 87-97.

Waddell, P., Bhat, C., Eluru, N., Wang, L. and Pendyala, R.M. (2007) Modeling interdependence in household residence and workplace choices, Transportation Research Record, 2003, pp. 84-92.

Weber, M. (1972) Wirtschaft und Gesellschaft (Tübingen: Mohr).

Zhou, J. and Golledge, R. (2007) Real-time tracking of activity scheduling/schedule execution within a unified data collection framework, Transportation Research A, 41, pp. 444-463. 
Figure 1: A conceptual model of travel behaviour

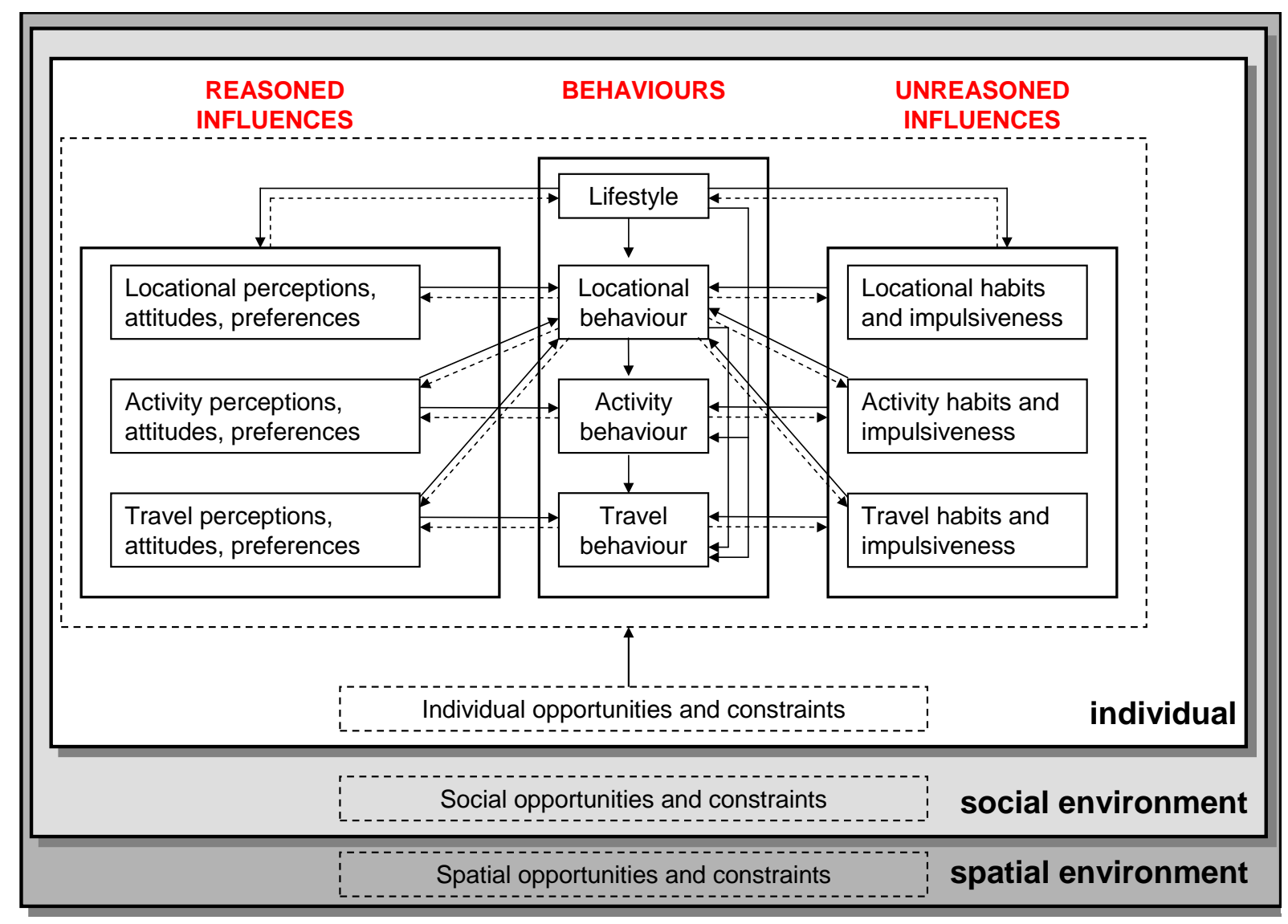

